\title{
Reversible Aging in Asphalt Binders ${ }^{\dagger}$
}

\author{
Simon A. M. Hesp,* Serban Iliuta, and John W. Shirokoff \\ Department of Chemistry, Queen's University, Kingston, Ontario, K7L 3N6 Canada
}

Received September 13, 2006. Revised Manuscript Received November 16, 2006

\begin{abstract}
X-ray diffraction, optical microscopy, and mass spectrometry techniques were used in an attempt to clarify the morphological and chemical features that are responsible for reversible aging processes that occur in asphalt binders during conditioning at low temperatures. The reversible aging term is used in this paper to capture all reversible processes (i.e., wax crystallization, free volume collapse, asphaltene aggregation, etc.) that lead to a reduction in low-temperature rheological and fracture performance. Crystalline content and asphaltene aggregate size at ambient temperatures, as measured by X-ray diffraction on thin asphalt films, are identified as two factors that correlate reasonably well with the reversible aging tendency at low temperatures. A coarse and unstable colloidal state for the asphaltene fraction is also identified as an important contributor to reversible aging. It was found that the saturates fraction has a particularly significant role in the aging process, with those asphalts containing higher amounts of linear paraffin losing more in terms of rheological performance. This important phenomenon is responsible for significant fracture distress in asphalt pavements in northern climates and therefore deserves further investigation. Some of the air-blown asphalts investigated in this study were found to show a high crystalline content and a coarse phase morphology and concurrent tendency for reversible aging during cold conditioning. This may be due to the crude source(s) employed, the chemistry of the air-blowing process, or resulting phase changes. Other air-blown binders did not show these features while they were still susceptible to reversible aging. Hence, the reason for this behavior appears to be due to multiple processes which are at present only poorly understood.
\end{abstract}

\section{Introduction}

Asphalt binders used for road paving applications in North America are graded according to the methods developed under the U.S. Strategic Highway Research Program, which concluded in the early 1990s. ${ }^{1-2}$ The grading approach is now known as the Superpave specification, as it was supposed to deliver superior performing pavements. However, recent research with pavement trials and regular paving contracts has shown that premature failures and excessive low-temperature cracking is still quite prevalent and that the performance grade (PG grade) provides only a crude measure of performance. ${ }^{3-10}$ The need for an improved specification has been recognized, and current

† Disclaimer: None of the sponsoring agencies necessarily concur with, endorse, or have adopted the findings, conclusions, or recommendations either inferred or expressly stated in subject data developed in this study.

* To whom correspondence should be addressed. E-mail: Simon.Hesp@ chem.queensu.ca.

$\doteqdot$ Faculty of Engineering and Applied Science, Memorial University of Newfoundland, St. John's, Newfoundland, A1B 3X5 Canada.

(1) Anderson, D. A.; Christensen, D. W.; Bahia, H. U.; Dongré, R.; Sharma, M. G.; Antle, C. E.; Button, J. SHRP-A-369 Binder Characterization and Evaluation. Volume 3: Physical Characterization; Strategic Highway Research Program, National Research Council, Washington, DC, 1994.

(2) Anderson, D. A.; Kennedy, T. W. J. Assoc. Asphalt Paving Technol. 1993, 62, 481-507.

(3) Button, J. W.; Hastings, C. P. Proc. Can. Tech. Asphalt Assoc. 1998 $43,48-72$.

(4) Planche, J. -P.; Lesueur, D.; Hines, M. L.; King, G. N. Evaluation Of Elastomer Modified Bitumens Using SHRP Binder Specification. Proceedings of the First Eurasphalt \& Eurobitume Congress, Strasbourg, France, May 7-10, 1996; Paper E\&E 5.121.

(5) Kandhal, P. S.; Dongré, R;, Malone, M. S. J. Assoc. Asphalt Paving Technol. 1996, 65, 491-531.

(6) Iliuta, S.; Hesp, S. A. M.; Marasteanu, M. O.; Masliwec, T.; Tam, K. K. J. Transportation Res. Board, Transportation Res. Rec. 2004, 1875, $14-21$. efforts are focused on developing a simple approach based on the Superpave framework but one that would be blind to manufacturing method and composition. ${ }^{7-13}$

The low-temperature grade of an asphalt binder is derived from its stiffness and relaxation ability as measured in the bending beam rheometer (BBR). The low-temperature grade should equal the minimum surface temperature that is reached only once in 50 years, thus providing a confidence level of $98 \%$ that in any given year the pavement will not be exposed to damaging temperatures. This strict limit is justified, as lowtemperature cracks, once present, are very difficult to repair. The stiffness at $60 \mathrm{~s}$ of loading time, $S(60)$, should remain under $300 \mathrm{MPa}$, while the absolute slope of the stiffness master curve, commonly known as the $m$-value, or $m(60)$, should remain above 0.3 , for an asphalt binder to be acceptable in a certain geographical location. If a binder fails these specification criteria

(7) Iliuta, S.; Andriescu, A.; Hesp, S. A. M.; Tam, K. K. Proc. Can Tech. Asphalt Assoc. 2004, 49, 123-158.

(8) Zhao, M. O.; Hesp, S. A. M. Int. J. Pavement Eng. 2006, 7 (3), 199211; http://www.tandf.co.uk/journals.

(9) Yee, P.; Aida, B.; Hesp, S. A. M.; Marks, P.; Tam, K. K. J. Transportation Res. Board, Transportation Res. Rec. 2006, 1962, 44-51.

(10) Bodley, T.; Andriescu, A.; Hesp, S. A. M.; Tam, K. K. J. Assoc. Asphalt Paving Technol. 2007, in press.

(11) LS-308-Method of Test for Determination of Performance Grade of Physically Aged Asphalt Cement Using Extended Bending Beam Rheometer (BBR) Method. In MTO Laboratory Testing Manual, revision 23; Ministry of Transportation of Ontario: Ontario, Canada, February 2006.

(12) LS-299 (Draft)-Method of Test for Asphalt Cement's Resistance to Fatigue Fracture Using Double-Edge-Notched Tension Test (DENT). In MTO Laboratory Testing Manual, revision 23; Ministry of Transportation of Ontario: Ontario, Canada, February 2006.

(13) LS-298 (Draft)-Method of Test for Asphalt Cement Grading for Fracture Performance Using Compact Tension Procedure. In MTO Laboratory Testing Manual; Ministry of Transportation of Ontario: Ontario, Canada, July 2005 
at $10 \mathrm{deg}$ above the pavement design temperature, it can only be used in a warmer geographical area. The $10 \mathrm{deg}$ of difference between the measurement and design temperature was introduced to reduce the loading time in the BBR from $2 \mathrm{~h}$ to $60 \mathrm{~s}$.

One drawback of the current specification is that the limit on the stiffness relied entirely on a single study from British Columbia, and the final limiting temperatures, $T(S(60)=300$ $\mathrm{MPa})$ and $T(m(60)=0.3)$, were never validated with actual field performance of sufficiently old pavements. ${ }^{1,2,14}$ It is now widely recognized that the BBR protocol is deficient, with some pavements showing large-scale low-temperature cracking just months after construction, and older pavement trials showing a wide range of distress for binders of nearly the same lowtemperature grades. ${ }^{3-10}$

It is our opinion that a significant number of premature and excessive pavement failures occur because the current specification testing approach, as embodied in the American Association of State Highway and Transportation Officials (AASHTO) standard M320, ${ }^{15}$ fails to consider the fact that asphalt binders are nonequilibrium systems just after preparation for BBR testing. The current specification test uses only $1 \mathrm{~h}$ of conditioning time prior to testing for stiffness and relaxation ability, while these binders if given more time would undergo significant internal structure formation, free volume collapse, and crystallization. Although the original specification contained an option to test binders after $24 \mathrm{~h}$ of conditioning, this provision never appears to have been widely accepted for reasons that are not well documented. Hence, the research described in this paper considers this issue in more detail with the objective of recommending changes to the way in which asphalt binders are currently accepted for a given low-temperature climate.

\section{Experimental Details}

Materials. The asphalt binders investigated in this study were obtained from a variety of sources. A listing of all materials and their pertinent properties is given in Table 1. Two sets of binders were obtained from pavement trials in Lamont, Alberta (1991), 8,16,17 and Timmins, Ontario (2003). ${ }^{7,10}$ The 14 binders obtained from these two trials were sampled during the construction of the test sections and had been stored in sealed cans at ambient temperatures until used for this study. Other binders were obtained through extraction from pavement cores ( $\mathrm{H} 1$ and $\mathrm{H} 2),{ }^{7}$ from the Materials Reference Library of the Strategic Highway Research Program as operated by Sierra Construction Engineering in Reno, Nevada (AAE), and from regular contracts and suppliers in Ontario (N1, N2, N3, E9, O1, and O2). ${ }^{9}$

Asphalt Binder Aging. All except the two recovered binders were aged in the laboratory according to standard procedures. Rolling thin-film oven aging according to AASHTO method $\mathrm{T}-240^{18}$ was followed by pressure aging vessel treatment at 100 ${ }^{\circ} \mathrm{C}$ for $20 \mathrm{~h}$ according to AASHTO method R-28. ${ }^{19}$

(14) Readshaw, E. E. Proc. Assoc. Asphalt Paving Technol. 1972, 42, $562-581$.

(15) AASHTO M320, Standard Specification for Performance-Graded Asphalt Binder; American Association of State Highway and Transportation Officials: Washington, D.C., 2002.

(16) Anderson, K. O.; Christison, J.; Bai, B.; Johnston, C. D.; Quinn, T.; McCullough, D. Proc. Can. Tech. Asphalt Assoc. 1998, 43, $16-47$.

(17) EBA Engineering Consultants Ltd. Performance Correlation for Quality Paving Asphalts. Test Roads Construction Report; Canadian Strategic Highway Research Program, Transportation Association of Canada: Ottawa, Canada, 1994.

(18) AASHTO T240, Effect of Heat and Air on a Moving Film of Asphalt (Rolling Thin Film Oven Test); American Association of State Highway and Transportation Officials: Washington, D.C., 2002.

(19) AASHTO R28, Accelerated Aging of Asphalt Binder Using a Pressurized Vessel (PAV); American Association of State Highway and Transportation Officials: Washington, D.C., 2002.
Table 1. Pertinent Asphalt Binder Properties ${ }^{a}$

\begin{tabular}{|c|c|c|c|}
\hline $\begin{array}{l}\text { asphalt } \\
\text { binders }\end{array}$ & source & $\begin{array}{l}\text { modification } \\
\text { type }\end{array}$ & grades \\
\hline $\mathrm{T} 1$ & $\begin{array}{l}\text { western } \\
\quad \text { Canadian }\end{array}$ & $\begin{array}{l}\text { Timmins, Ontario } \\
\text { RET + PPA }\end{array}$ & PG 64-34 \\
\hline $\mathrm{T} 2$ & unknown & oxidized & PG 64-34 \\
\hline T3 & unknown & SBS & PG 64-34 \\
\hline $\mathrm{T} 4$ & unknown & SBS + acid-modified & PG 64-34 \\
\hline T5 & unknown & SBS & PG 64-34 \\
\hline T6 & unknown & oxidized & PG 58-34 \\
\hline $\mathrm{T} 7$ & unknown & acid-modified & PG 52-34 \\
\hline L1 & Boundary Lake & $\begin{array}{l}\text { Lamont, Alberta } \\
\text { oxidized }\end{array}$ & 80/100 A, PG 58-22 \\
\hline L2 & $\begin{array}{l}\text { Montana/ } \\
\text { Bow River }\end{array}$ & straight & $150 / 200 \mathrm{~B}, \mathrm{PG} 52-28$ \\
\hline L3 & Cold Lake & straight & $300 / 400 \mathrm{~A}, \mathrm{PG} 46-34$ \\
\hline L4 & Redwater & straight & 80/100 C, PG 58-22 \\
\hline L5 & Lloydminster & oxidized & $80 / 100$ A, PG 64-28 \\
\hline L6 & Lloydminster & straight & $150 / 200$ A, PG 52-28 \\
\hline L7 & Cold Lake & straight & 200/300 A, PG 52-34 \\
\hline $\mathrm{H} 1$ & Lloydminster & $\begin{array}{l}\text { Hearst, Ontario } \\
\text { straight }\end{array}$ & 150/200 A, PG 52-33 \\
\hline $\mathrm{H} 2$ & Venezuelan & straight & $150 / 200 \mathrm{~B}, \mathrm{PG} 52-33$ \\
\hline N1 & unknown & $\begin{array}{l}\text { Northern Ontario } \\
\text { straight }\end{array}$ & PG 52-34 \\
\hline $\mathrm{N} 2$ & unknown & straight & PG 52-34 \\
\hline N3 & unknown & acid-modified & PG 52-34 \\
\hline E9 & unknown & acid-modified & PG $52-40$ \\
\hline $\begin{array}{l}\text { AAE } \\
\text { O1 } \\
\text { O2 }\end{array}$ & $\begin{array}{l}\text { Lloydminster } \\
\text { unknown } \\
\text { unknown }\end{array}$ & $\begin{array}{l}\text { Various Oxidized } \\
\text { oxidized } \\
\text { oxidized } \\
\text { oxidized }\end{array}$ & $\begin{array}{l}\text { 60/70, PG 70-22 } \\
\text { PG 58-34 } \\
\text { PG 58-34 }\end{array}$ \\
\hline
\end{tabular}

${ }^{a}$ Note: $\mathrm{RET}=$ reactive ethylene terpolymer; $\mathrm{PPA}=$ polyphosphoric acid; SBS = styrene-butadiene-styrene copolymer. Penetration grades are according to the Canadian Government Standards Board specification while PG grades are according to AASHTO M320.

Extended Bending Beam Rheometer Testing. The susceptibility to reversible aging at low temperatures was measured according to a new test method developed in Ontario, LS-308-Method of Test for Determination of Performance Grade of Physically Aged Asphalt Cement Using Extended Bending Beam Rheometer (BBR) Method. ${ }^{8-11}$

In brief, the BBR samples were stored at both 10 and $20{ }^{\circ} \mathrm{C}$ above their PG grade temperature for 1,24 , and $72 \mathrm{~h}$, after which the limiting temperatures were measured, where the stiffness at 60 $\mathrm{s}$ of loading reaches $300 \mathrm{MPa}$ or the slope of the creep stiffness master curve, the so-called $m$-value, reaches 0.3 , according to AASHTO M320 criteria. The warmest limiting temperature was used to determine the worst grade loss from the $1 \mathrm{~h}$ value in order to rank the binders for their reversible aging tendency.

X-ray Diffraction. Samples were prepared as thin films on glass slide holders by heating to $150{ }^{\circ} \mathrm{C}$ for $10 \mathrm{~min}$ in a drying oven followed by removal and air cooling to room temperature. The $\mathrm{X}$-ray diffraction spectra were obtained from these films as prepared, as well as at 1 and 6 weeks after preparation. X-ray diffraction measurements were performed on a Rigaku D/Max-2200V-PC machine using monochromated $\mathrm{Cu} \mathrm{K} \alpha$ radiation operating at 40 $\mathrm{kV}$ and $40 \mathrm{~mA}$. The scan range used was $5-110^{\circ} 2 \theta$ at a scan rate of $0.01^{\circ} 2 \theta \mathrm{s}^{-1}$ and a count time of $5 \mathrm{~s} / \mathrm{step}$. The instrument was set up with a divergence slit of $0.5^{\circ}$ and a receiving slit of $0.3 \mathrm{~mm}$. The full width at half-maximum and profile fits were obtained by using a Pearson VII and fixed background over the ranges of 5-35 $2 \theta$ and $60-110^{\circ} 2 \theta$.

The various morphological parameters were obtained according to the relationships first used for the characterization of precipitated asphaltenes by Yen and co-workers. ${ }^{20-22} \mathrm{~A}$ general representation of an asphaltene cluster in whole bitumen is given in Figure 1, which defines the parameters investigated by Yen in his studies of 1587. 


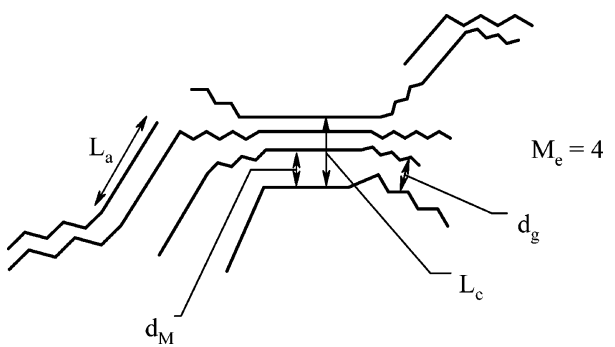

Figure 1. Schematic asphaltene micellar structure: ${ }^{20} d_{\mathrm{M}}=$ distance between aromatic sheets, $d_{\gamma}=$ distance between aliphatic chains, $L_{\mathrm{a}}=$ aromatic sheet diameter, $L_{\mathrm{c}}=$ cluster size, $M_{\mathrm{e}}=$ number of sheets in cluster.

(a)

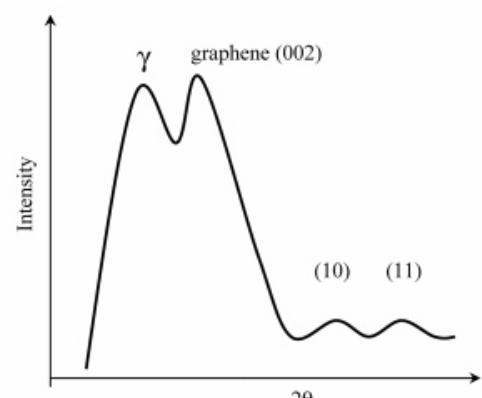

(b)

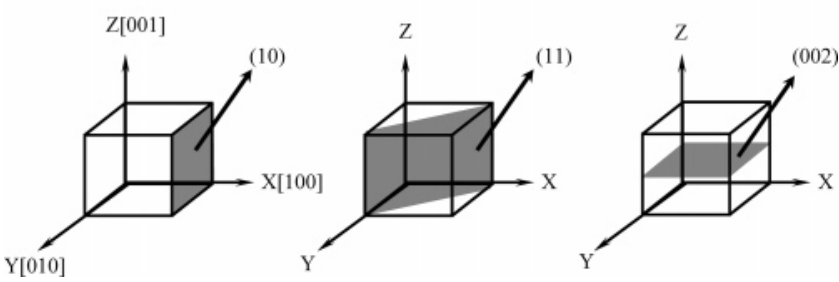

Figure 2. (a) Schematic of X-ray diffraction pattern and (b) diffraction planes in asphaltene structures (after Siddiqui et al.). Reprinted with permission from ref 23. 2002 American Chemical Society.

the structure of asphaltenes. A typical schematic X-ray diffraction spectrum for an asphaltene fraction is provided in Figure 2, showing the $\gamma$, graphene (002), (10), and (11) peaks. Aromaticity $\left(f_{\mathrm{a}}\right)$, aromatic sheet diameter $\left(L_{\mathrm{a}}\right)$, cluster size $\left(L_{\mathrm{c}}\right)$, interlayer distance between aromatic sheets $\left(d_{\mathrm{M}}\right)$, interchain distance $\left(d_{\gamma}\right)$, and number of sheets per cluster $\left(M_{\mathrm{e}}\right)$ were all obtained from the X-ray diffraction pattern according to standard procedures..$^{20-24}$

The aromaticity, $f_{\mathrm{a}}$, was calculated from the areas of the $\gamma$ and graphene bands in the X-ray diffraction pattern:

$$
f_{\mathrm{a}}=C_{\mathrm{A}} / C=C_{\mathrm{A}} /\left(C_{\mathrm{A}}+C_{\mathrm{S}}\right)=A_{\text {graphene }} /\left(A_{\text {graphene }}+A_{\gamma}\right)
$$

where $f_{\mathrm{a}}$ is the percentage of carbon atoms in aromatic structures, $C_{\mathrm{A}}$ is the number of aromatic carbon atoms, $C_{\mathrm{S}}$ is the number of saturate carbon atoms, $A_{\text {graphene }}$ is the area of the graphene band, and $A_{\gamma}$ is the area of the $\gamma$ band.

The distance between the aromatic sheets, $d_{\mathrm{M}}$, was calculated according to Bragg's law, with the peak in the graphene band providing the characteristic wavelength of the scattering event:

$$
d_{\mathrm{M}}=\lambda /(2 \sin \theta)
$$

where $d_{\mathrm{M}}$ is the interlayer distance, $\lambda$ is the wavelength of the $\mathrm{Cu}$ $\mathrm{K} \alpha$ radiation, and $\theta$ is Bragg's angle.

(21) Wen, C. S.; Chilingarian, G. V.; Yen, T. F. Properties and Structure of Bitumens. In Bitumens, Asphalts and Tar Sands; Chilingarian, G. V., Yen, T. F., Eds.; Developments in Petroleum Science 7; Elsevier Scientific Publishing Co.: Amsterdam, 1978; Chapter 7, p 155.

(22) Schwager, I.; Farmanlan, P. A.; Kwan, J. T.; Weinberg, V. A.; Yen, T. F. Anal. Chem. 1983, 55, 42 .

(23) Siddiqui, M. N.; Ali, M. F.; Shirokoff, J. Fuel 2002, 81, 51-58.
The distance between the saturated portions of the cluster was calculated according to the following relationship:

$$
d_{\gamma}=5 \lambda /(8 \sin \theta)
$$

The average diameter of an aromatic sheet is given by Scherrer's equation for crystallite size:

$$
L_{\mathrm{a}}=1.84 \lambda /(\omega \cos \theta)=0.92 / B_{1 / 2}
$$

where $B_{1 / 2}$ is the full width at half-height for the (11) band and $\omega$ is the bandwidth.

The average height of the stack of aromatic sheets perpendicular to the sheet plane was calculated according to the following relationship:

$$
L_{\mathrm{c}}=0.9 \omega \cos \theta=0.45 / B_{1 / 2}
$$

where $B_{1 / 2}$ is the full width at half-height for the graphene band.

Finally, the number of sheets in a stack is calculated according to the following relationship:

$$
M_{\mathrm{e}}=\left(L_{\mathrm{c}} / d_{\mathrm{M}}\right)+1
$$

Optical Microscopy. All samples were observed under both fluorescence and phase contrast modes with a Leica optical microscope using a 1.3 numerical aperture and $100 \times$ Fluotar oil immersion lens. Fluorescence excitation was done at $488 \mathrm{~nm}$, while detection occurred at $520 \mathrm{~nm}$. Images were collected with a chargecoupled device (CCD) camera in both fluorescence and phase contrast modes with constant gray scale levels. The images in this paper contain a superimposed false green color, providing the fluorescence information, and a false blue color, providing the phase contrast information. All images were exported as TIFF files with $1344 \times 1024$ pixels and $0.06 \mu \mathrm{m} /$ pixel. The limiting resolution provided by the oil immersion lens was approximately $0.2 \mu \mathrm{m}$.

Mass Spectrometry. The mass spectra for the saturates fractions of 655-1 and 655-2 were obtained using a Waters Micromass GCT time-of-flight mass spectrometer. It was equipped with an electron impact (EI) source, and the instrument was run in positive mode at an electron energy of $70 \mathrm{eV}$. Aliquots of approximately $1 \mu \mathrm{L}(\sim 30$ $\mathrm{mg} / \mathrm{mL}$ sample in $\mathrm{CH}_{2} \mathrm{Cl}_{2}$ ) were used in the analysis.

\section{Results and Discussion}

The results obtained for the reversible aging tests according to LS-308 are given in Figure 3. This graph lists only the worst 3-day grade loss, as determined by storing the samples at both 10 and $20^{\circ} \mathrm{C}$ above their Superpave low-temperature grade. The 3-day test is used as a compromise since pavements in northern climates typically cool for periods of weeks rather than days. Three days of conditioning will provide nearly $75 \%$ of the grade loss that would occur over a 2 -week period.

It is obvious from the results that the variation in grade loss between binders is significant. Given the fact that a loss of 6 ${ }^{\circ} \mathrm{C}$ can reduce the confidence that a given road is not exposed to damaging temperatures from $98 \%$ to less than $50 \%$, it is an issue that deserves more attention than it is currently given. Superior binders such as T1 (made with a base asphalt from Lloydminster, Alberta) and L3 and L7 (both from Cold Lake, Alberta) lose close to nothing. In contrast, inferior binders such as T2, L1, L4, E9, and O1 (all oxidized or acid modified) lose considerable amounts, from 7.6 to $14{ }^{\circ} \mathrm{C}$. The relative performance of these binders in service is discussed elsewhere. ${ }^{7-10}$ However, to illustrate by how much the 3-day test can improve the predictive ability of the BBR method for low-temperature

(24) Shirokoff, J. W.; Siddiqui, M. N.; Ali, M. F. Energy Fuels 1997 , $11,561-565$. 


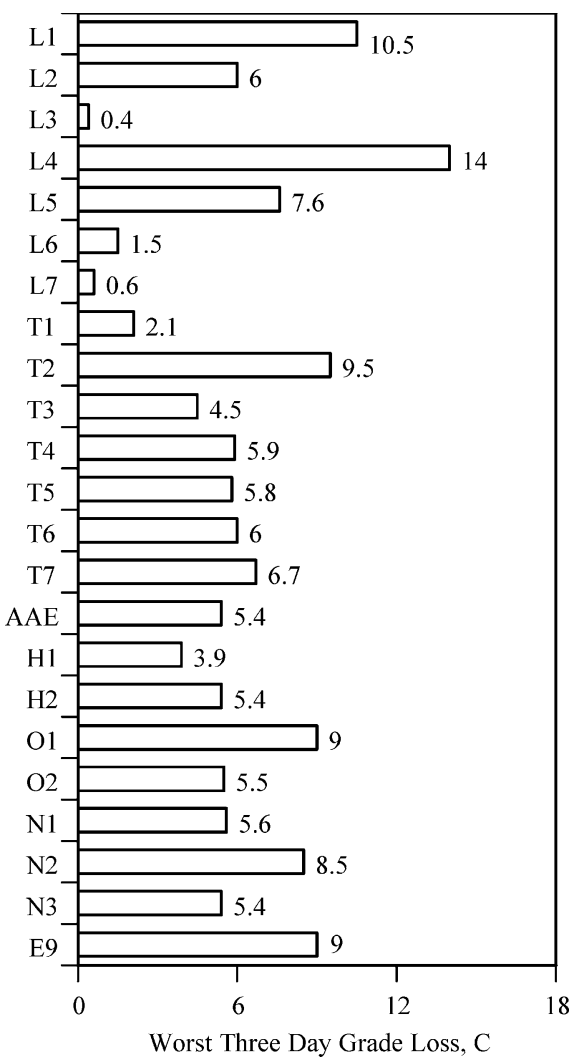

Figure 3. Worst 3-day grade losses.

distress, some results for the Lamont, Alberta, trial are given in Figure $4 .{ }^{8}$ It is obvious from this figure that there is a significant improvement due to conditioning and that likely there is a cause and effect relationship between reversible aging and excessive transverse cracking. The improvement for performance prediction was also found for binders that were used in an SPS9A pavement trial in Petawawa, Ontario, ${ }^{7}$ and for those that were used in the Highway 655 trial in Timmins, Ontario. ${ }^{7,10}$ However, the focus of this paper is to investigate what chemical and/or morphological properties are of importance for the reversible aging process.

The literature on reversible aging is extensive, ranging back to the $1930 \mathrm{~s},{ }^{25-27} 1950 \mathrm{~s},{ }^{28,29}$ and $1970 \mathrm{~s} .{ }^{30}$ Some authors claim that the effect is not important for low-temperature cracking, while others are unsure or support the belief that it causes increased distress. Although the early work recognized that airblown (oxidized) binders reversibly age considerably more than straight-distilled materials, these papers are largely silent on what molecular and morphological factors could explain these differences. In contrast, recent studies have focused on the factors (chemical and structural) that are of importance in the reversible aging process, but there is still much disagreement in the literature.

Bahia $^{31}$ concluded that the hardening phenomenon was largely due to free volume collapse and that slow crystallization and

(25) Coombs, C. E.; Traxler, R. N. J. Appl. Phys. 1937, 8, 291-296.

(26) Traxler, R. N.; Schweyer, H. E. Proc., Am. Soc. Test. Mater. 1936, 36 (II), 544-550.

(27) Traxler, R. N.; Coombs, C. E. Proc., Am. Soc. Test. Mater. 1937, 37 (II), 549-555.

(28) Brown, A. B.; Sparks, J. W.; Smith, F. M. Proc. Assoc. Asphalt Paving Technol. 1957, 26, 486-494.

(29) Brown, A. B.; Sparks, J. W. Proc. Assoc. Asphalt Paving Technol. 1958, 27, 35-51.

(30) Struik, L. C. E. Physical Ageing in Amorphous Polymers and Other Materials; Elsevier Scientific Publishing Co.: Amsterdam, 1978.

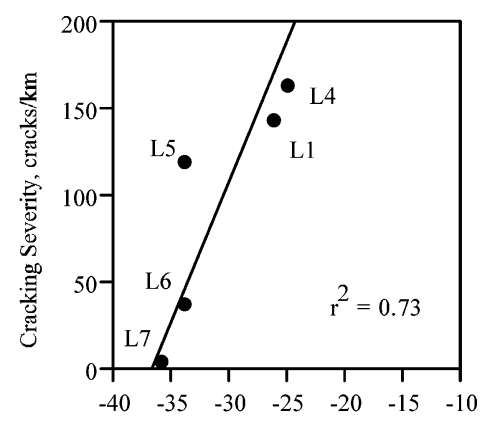

(a)

M320 Grade Temperature, C

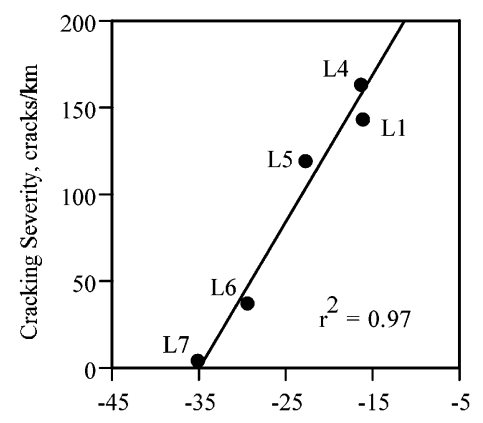

(b)

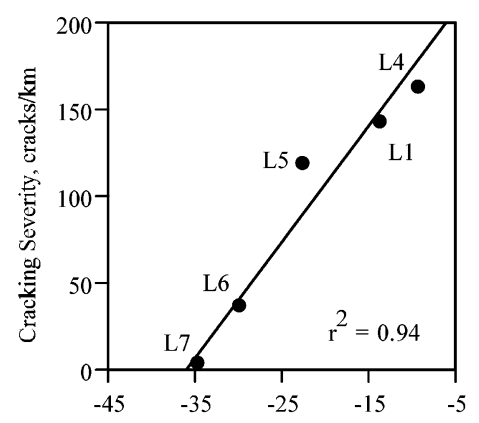

(c)

LS-308 after 3 days, $C$

Figure 4. Cracking severity versus (a) AASHTO M320 and (b and c) LS-308 grading temperatures for Lamont, Alberta, C-SHRP pavement trial binders (after Zhao and Hesp). Reprinted with permission from ref 8. 2006 Taylor and Francis Journals.

aggregation processes were unlikely contributors to reversible aging (physical hardening). This conclusion was later disputed by Planche and co-workers ${ }^{32,33}$ and Anderson and Marasteanu, ${ }^{34}$ who argued that the physical hardening rate was a strong function of the wax content. More recently, $\mathrm{Lu}$ and co-workers have stated that there "was no simple relation between asphalt cracking and bitumen wax content", 35 a conclusion with which Soenen and co-workers agreed, stating that "there is no direct relationship with the wax content." 36 Dongré 37 argued that the entire phenomenon is not important, while Romero and co-

(31) Bahia, H. U. Low Temperature Isothermal Physical Hardening of Asphalt Cements. Ph.D. Thesis, Pennsylvania State University, State College, PA, 1991.

(32) Claudy, P.; Létoffé, J. M.; Rondelez, F.; Germanaud, L.; King, G. N.; Planche, J.-P. Prepr. Pap.-Am. Chem. Soc., Div. Fuel Chem. 1992, $37,1408$.

(33) Planche, J. P.; Claudy, P. M.; Létoffé, J. M.; Martin, D. Thermochim. Acta 1998, 324, 223-227.

(34) Anderson, D. A.; Marasteanu, M. O. J. Transportation Res. Board, Transportation Res. Rec. 1999, 1661, 27-34.

(35) Lu, X.; Soenen, H.; Redelius, P. Impact of Bitumen Wax on Asphalt Performance-Low Temperature Cracking. Proceedings of the Third Eurobitume \& Eurasphalt Congress, Vienna, Austria, May 12-14, 2004; Paper 50, Session 4. 
workers ${ }^{38}$ argued that it is only important for certain binders in combination with specific aggregates. A drawback of the studies published on reversible aging is that they were only concerned with laboratory tests, often included a limited number of binders, and were lacking field performance data.

Basu and co-workers tested a group of nine binders that had all been used in test sections in Ontario. ${ }^{39}$ They found that these binders lost anywhere from 3 to $10{ }^{\circ} \mathrm{C}$ after 3 days of conditioning at their grading temperatures. The binders investigated included straight-run and oxidized as well as polymermodified materials. These and other binders were later investigated by Iliuta and co-workers, ${ }^{6,7}$ who found the correlation between the grade temperatures after 3 days of conditioning and the probable cracking onset temperatures in the test sections to be much stronger than the correlation with the regular AASHTO M320 grade temperatures. Zhao and Hesp ${ }^{8}$ studied the reversible aging effect for the binders used in the C-SHRP trial in Lamont, Alberta, and found there to be a strong relationship between the tendency to age during conditioning and the severity of the transverse cracking distress (see Figure 4). To the best of our knowledge, these results are the first and only to indicate with field distress data that the reversible aging phenomenon is a probable and serious cause of early distress in many northern pavements.

However, the above (condensed) review of the recent literature also shows that there is still significant uncertainty about what morphological and chemical features are of importance for this phenomenon. Hence, this study was undertaken on a large number of well-characterized binders in an attempt to shed light on the issue. X-ray diffraction, optical microscopy, and mass spectrometry techniques were employed in order to obtain the desired information.

The X-ray diffraction data are considered first. Aromaticities as measured from the graphene and $\gamma$ bands in the X-ray diffraction spectrum varied from a low of 0.4 (L4) to a high of 0.65 (T6). The distances between aromatic sheets $\left(d_{\mathrm{M}}\right)$ and saturated chains in the cluster $\left(d_{\gamma}\right)$ varied by insignificant amounts. Significant differences between wax content, aromatic sheet size $\left(L_{\mathrm{a}}\right)$, and cluster size $\left(L_{\mathrm{c}}\right.$ or $\left.M_{\mathrm{e}}\right)$ were found, and these will be discussed next.

Figure 5 shows the worst 3-day grade loss as measured by LS-308 versus the area in the X-ray diffraction spectrum that relates to the wax content. The data are interesting from several perspectives. First, there appear to be no binders with a high wax content and low grade loss. This provides indirect evidence that the amount of wax in the binder at room temperature is an indicator of the tendency for the material to reversibly age at lower temperatures. This observation would agree with the work by Planche and co-workers ${ }^{32,33}$ and Anderson and Marasteanu, ${ }^{34}$ who concluded that wax is important. Second, there are a significant number of binders with little detectable wax at room temperature but which still lose a considerable amount when stored at lower temperatures. For instance, binders E9, O1, N2, and L5 all lose more than $6{ }^{\circ} \mathrm{C}$ yet show very little detectable

(36) Soenen, H.; Ekblad, J.; Lu, X.; Redelius, P. Isothermal Hardening in Bitumen and in Asphalt Mix. Proceedings of the Third Eurobitume \& Eurasphalt Congress, Vienna, Austria, May 12-14, 2004; Paper 135, Session 4.

(37) Dongré, R. Effect of Physical Hardening on Relaxation Behaviour of Asphalt Binders. Proceedings of the Second Eurasphalt \& Eurobitume Congress, Barcelona, Spain, September 20-22, 2000; Book I, pp 220228 .

(38) Romero, P.; Youtcheff, J.; Stuart, K. J. Transportation Res. Board, Transportation Res. Rec. 1999, 1661, 22-27.

(39) Basu, A.; Marasteanu, M. O.; Hesp, S. A. M. J. Transportation Res. Board, Transportation Res. Rec. 2003, 1829, 1-7.

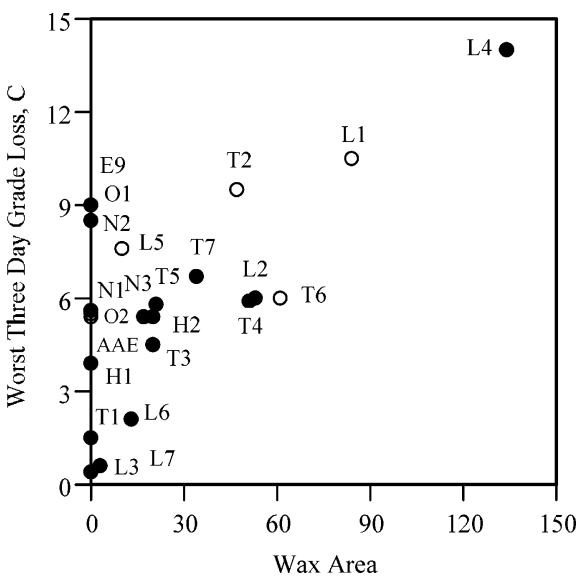

Figure 5. Worst 3-day grade loss versus wax area in the X-ray diffraction spectrum. Note: open symbols are for oxidized binders.

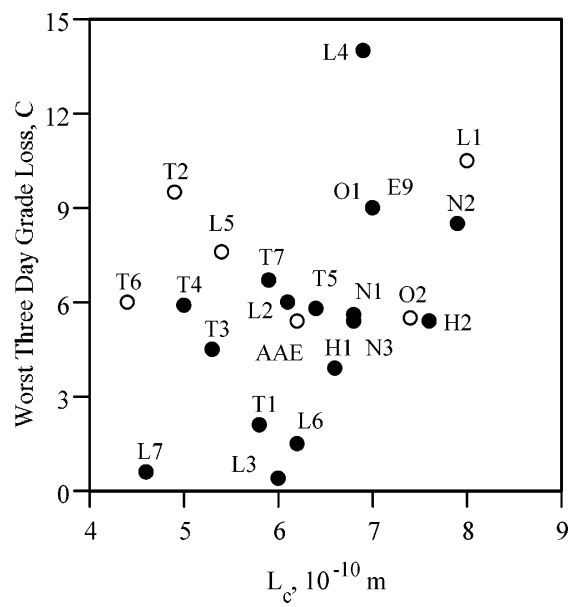

Figure 6. Worst 3-day grade loss versus asphaltene cluster size in the X-ray diffraction spectrum. Note: open symbols are for oxidized binders.

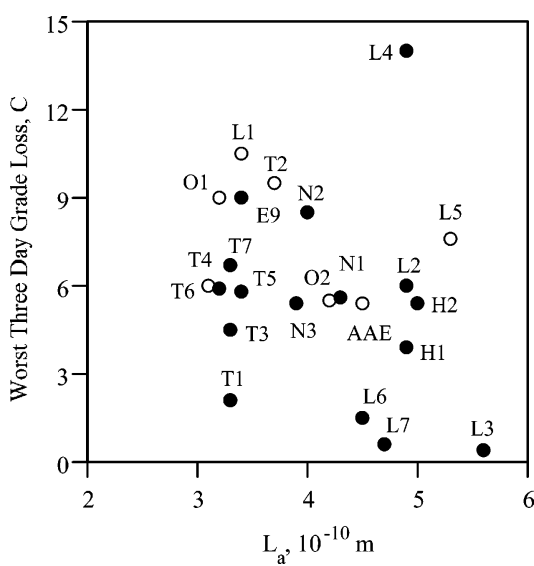

Figure 7. Worst 3-day grade loss versus asphaltene sheet size in the X-ray diffraction spectrum. Note: open symbols are for oxidized binders.

wax in the X-ray diffraction spectrum. This could be due to a small size and poor quality for the wax crystals, making them difficult to detect by X-ray diffraction, or perhaps, there are other reasons.

Additional insight is obtained from considering the cluster sizes $\left(L_{\mathrm{c}}\right)$ and the size of the aromatic sheets in the asphaltene structure $\left(L_{\mathrm{a}}\right)$. Figures 6 and 7 provide plots of the worst 3-day grade losses versus both parameters. These data suggest there is a second factor of importance aside from the wax content. Binders E9, O1, and N2 all possess a relatively large cluster 
L1

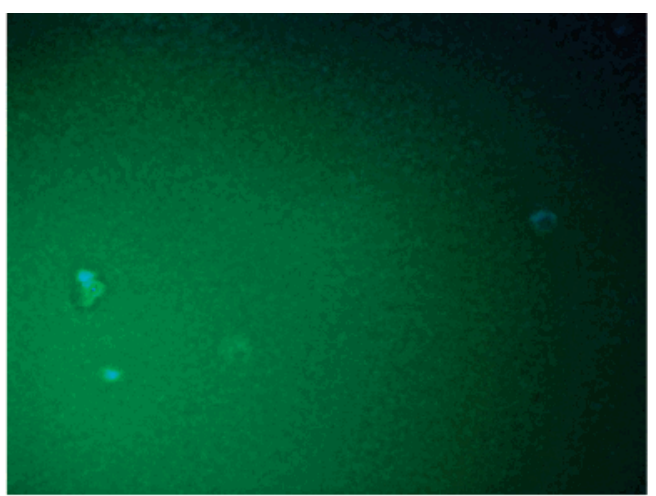

L3

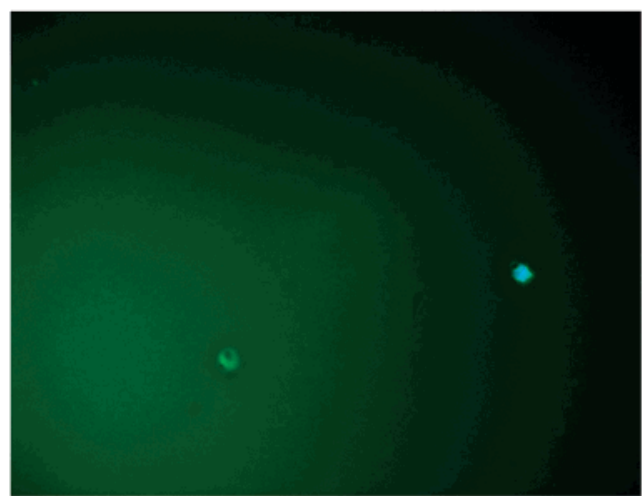

L5

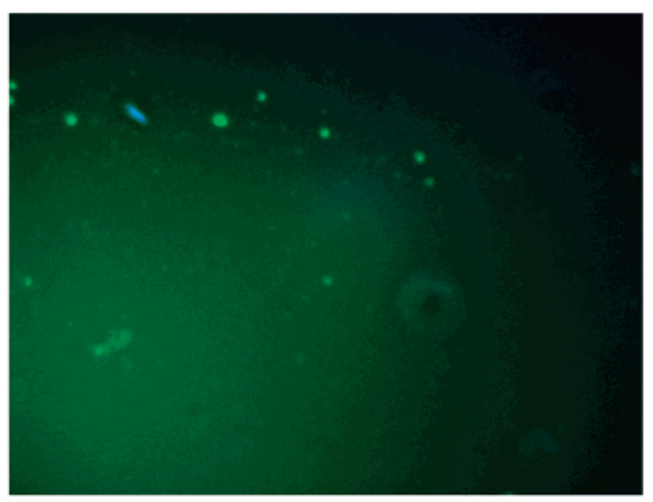

L7

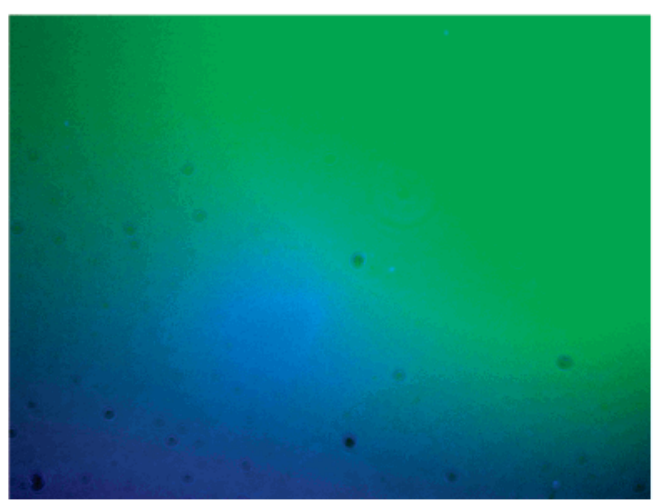

L2

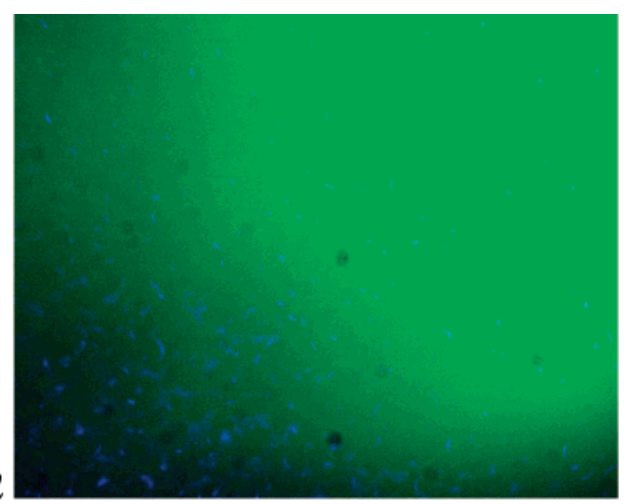

L4

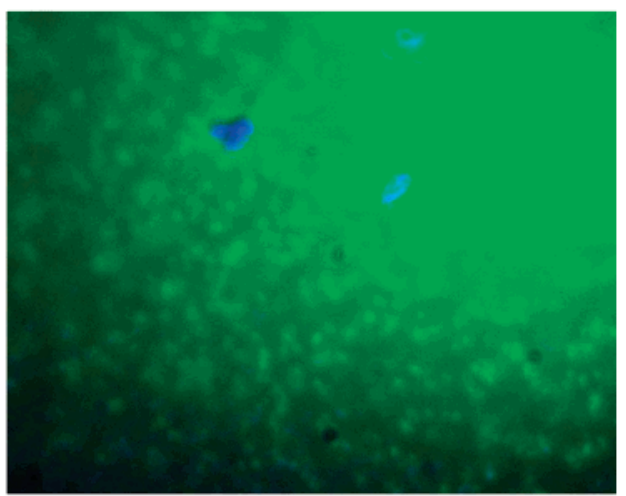

L6

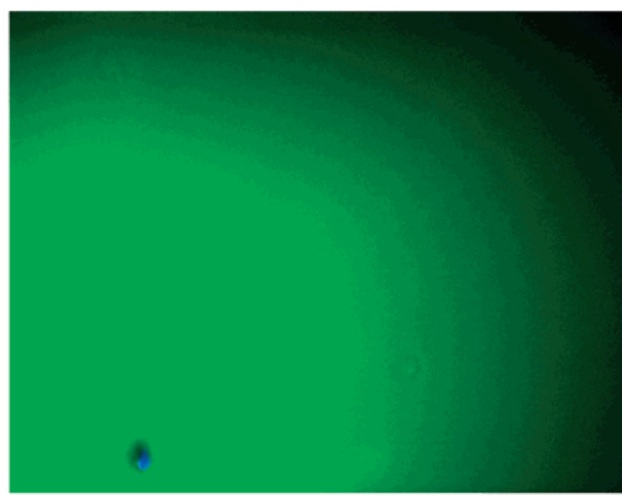

Figure 8. Fluorescence (green) and phase contrast (blue) images of Lamont, Alberta, C-SHRP binders.

size $\left(L_{\mathrm{c}}\right)$ and small aromatic sheet size $\left(L_{\mathrm{a}}\right)$. It is likely that this leads to high levels of reversible aging due to an immobilization of the structures at relatively high temperatures during the cooling process. Such immobilized structures would require a long time to equilibrate and hence give AASHTO M320 grading results that are not reflective of true performance.

Since the X-ray diffraction technique only provides information at and below the asphaltene cluster level, an additional method, optical microscopy, was employed. Figures 8-10 provide the images in both fluorescence and phase contrast modes for the Lamont, Alberta (Figure 8), Timmins, Ontario (Figure 9), and miscellaneous (Figure 10) binders. The superior performing binders in the Lamont (L3 and L7) and Timmins (T1) trials show a very homogeneous image with little or no structure. (Note that the fluorescence lamp was slightly misaligned making the phase contrast information more noticeable in one corner of the image.) The poorly performing binders from the Lamont trial show either a two-phase structure indicating 
$\mathrm{T} 1$

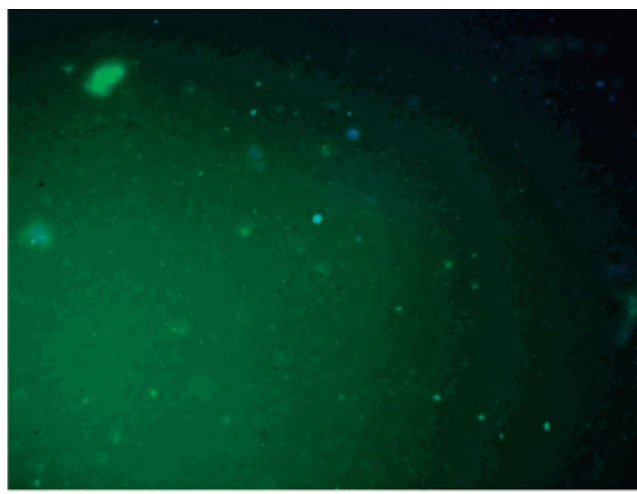

$\mathrm{T} 3$

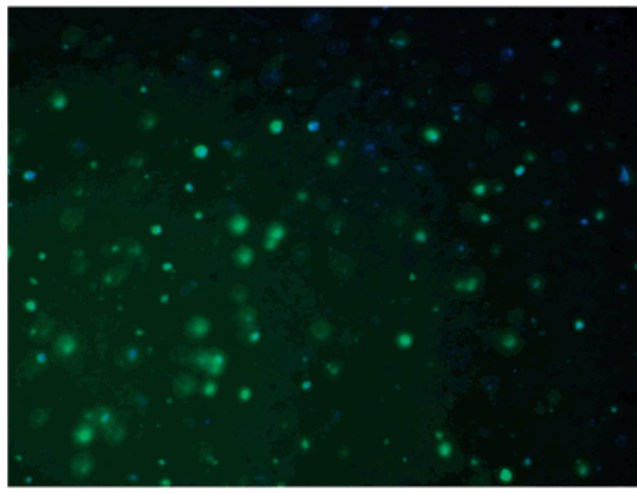

T5

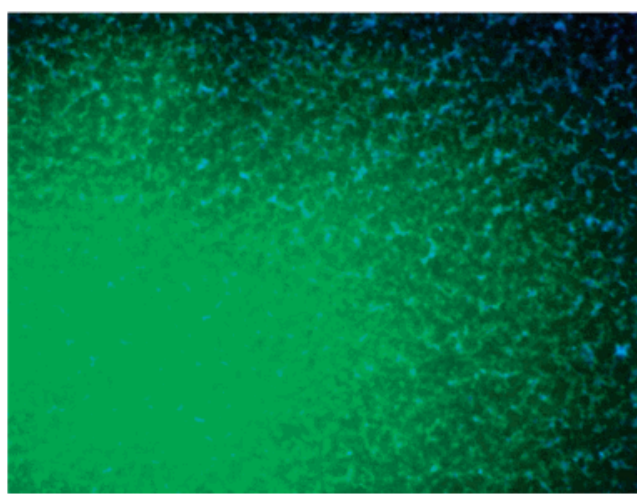

T7

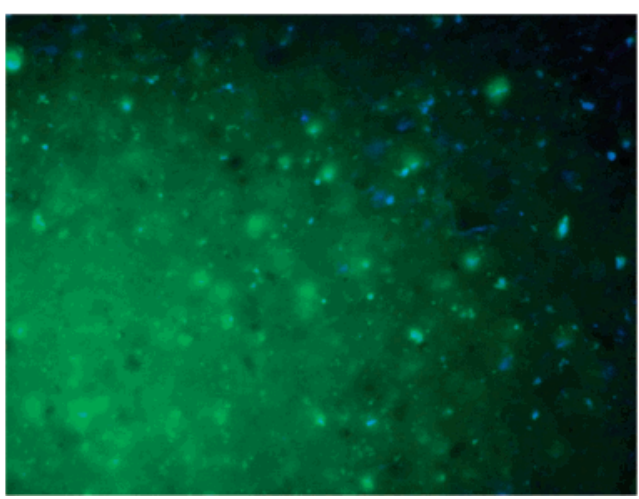

$\mathrm{T} 2$

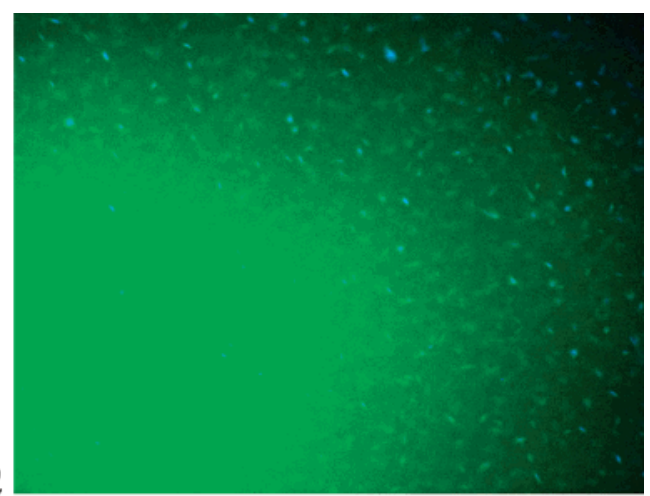

T4

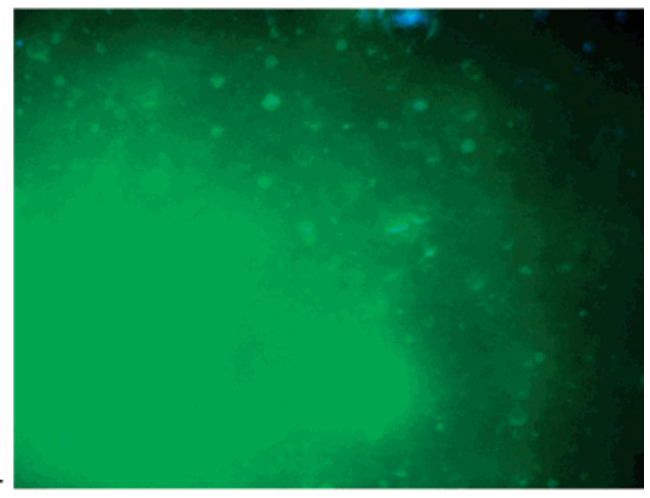

T6

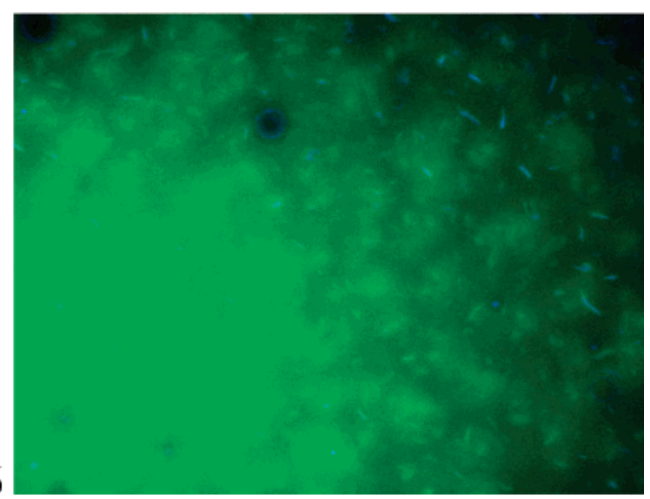

Figure 9. Fluorescence (green) and phase contrast (blue) images of the Timmins, Ontario, trial binders.

wax (L2 and L4) or a homogeneous image (L1 and L5). Hence, it is still unclear what caused the poor performance of binder L5, which was also found to be low in detectable wax. L5 has a large asphaltene sheet size (see Figure 7), but the same holds for L3 which is almost unchanged by low-temperature conditioning. It is likely that the phase structure and hence phase compatibility at lower temperatures are less favorable for the oxidized L5 binder. Similarly, binder AAE (oxidized Lloydminster) also shows a very homogeneous structure but loses considerably more in LS-308 $\left(5.4{ }^{\circ} \mathrm{C}\right)$ compared to straight- run Lloydminster, L6 $\left(1.5^{\circ} \mathrm{C}\right)$. Another possible reason for this discrepancy is that the grade loss is associated with the crystallization of poorly defined microcrystalline material that is not detected by either X-ray or optical microscopy techniques.

The binders from the Timmins trial show a range of features, with T2 and T6 showing signs of wax crystals, T5 showing signs of a high polymer concentration, and T3 showing signs of low fluorescence and hence likely a tendency for premature hardening due to chemical aging and volatilization. Binders T4 and $\mathrm{T} 7$ both produced by the same supplier also show a 
H1

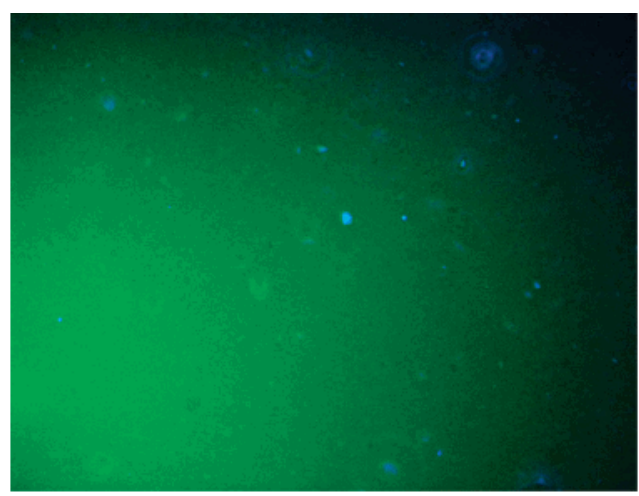

N1
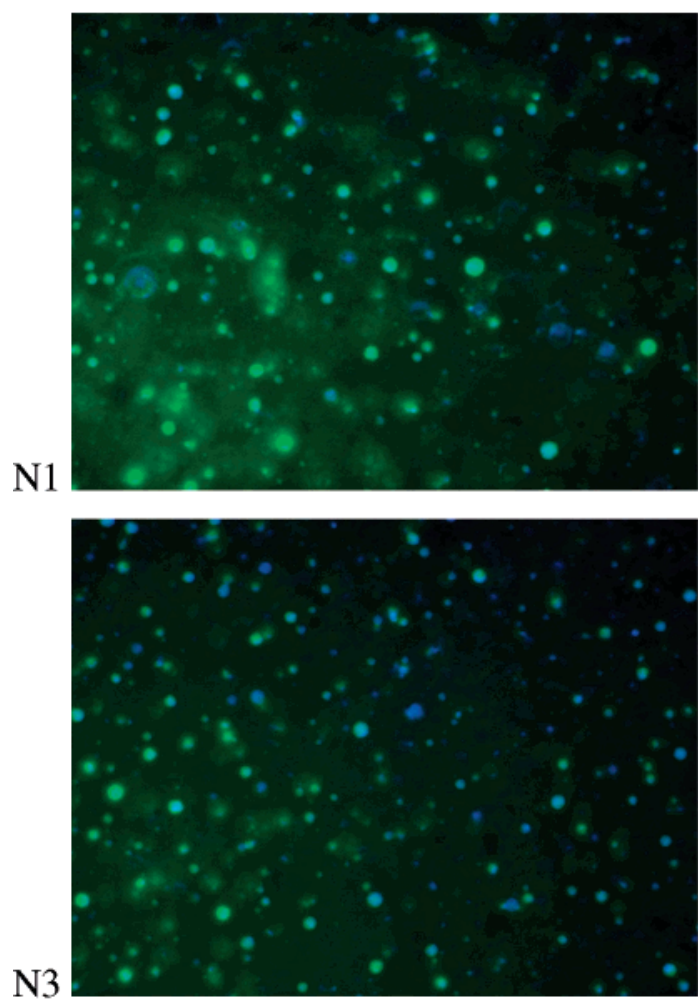

E9

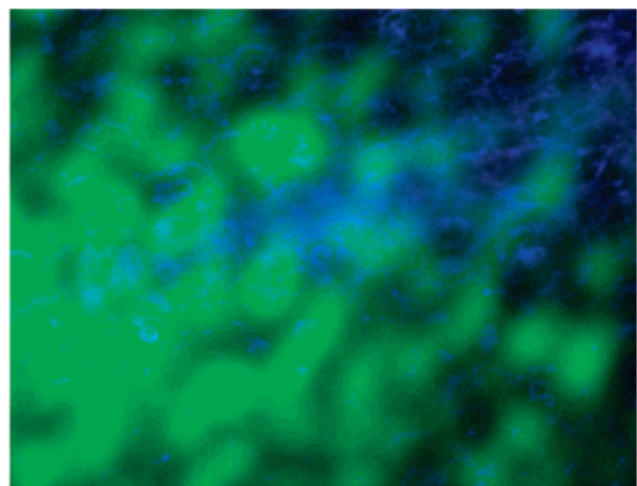

$\mathrm{H} 2$

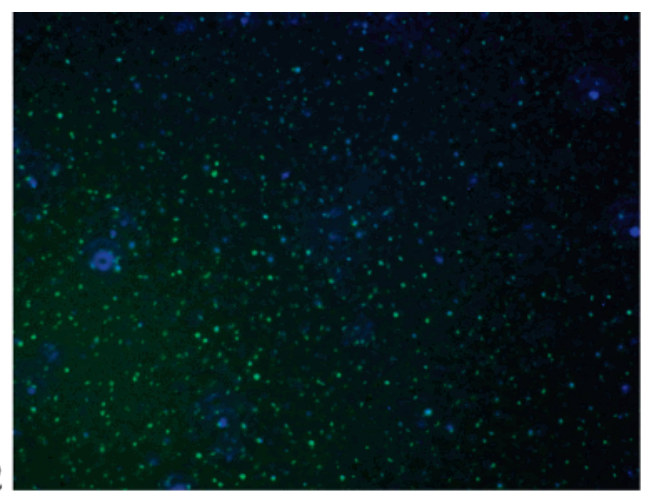

$\mathrm{N} 2$

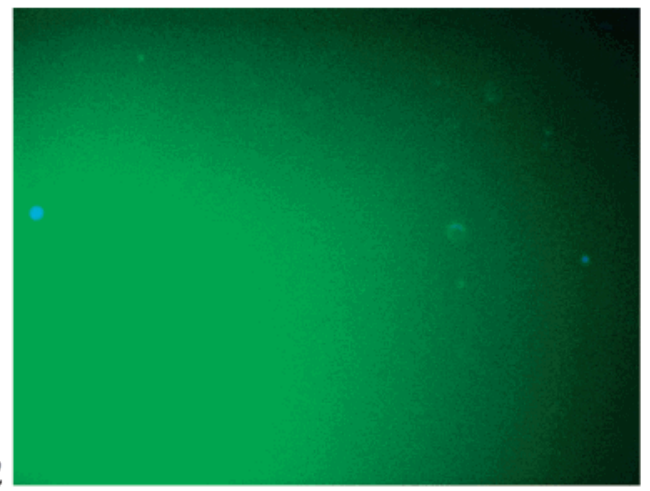

AAE

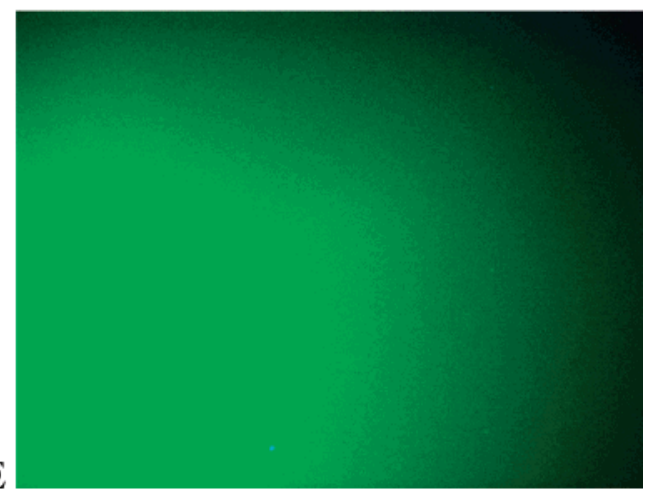

Figure 10. Fluorescence (green) and phase contrast (blue) images of miscellaneous asphalt binders.

reasonable amount of structure, which shows up in their tendency to reversibly age at low temperatures. Only binder $\mathrm{T} 1$ shows little structure, likely because it was made with Lloydminster asphalt.

Binders H1 and H2 were both used in the 1991 C-SHRP pavement trial in Hearst, Ontario. ${ }^{7}$ They were graded equally at $-33{ }^{\circ} \mathrm{C}$ when the test sections were constructed. However, after 12 years in service, the test section constructed with $\mathrm{H} 1$ showed 50 cracks $/ \mathrm{km}$, while the section constructed with $\mathrm{H} 2$ showed $500 \mathrm{cracks} / \mathrm{km}$. This difference is in part because $\mathrm{H} 2$ reversibly ages more than $\mathrm{H} 1$ but also because $\mathrm{H} 2$ had chemically aged by much more than $\mathrm{H} 1$. The fluorescence images show that $\mathrm{H} 2$ has a predominantly paraffin composition (low fluorescence) with considerable structure, while H1 shows a higher aromatics content (higher fluorescence) without much structure (Lloydminster asphalt). The aromatic contents, as measured by X-ray diffraction, were 0.52 for $\mathrm{H} 1$ and 0.43 for $\mathrm{H} 2$, supporting the fluorescence results.

Binders N1 and N2 suffered severe cracking after only the first winter of service for two northern Ontario contracts, while 
binder N3, used in a contract several kilometers away from N2, showed almost no cracking. ${ }^{9}$ These experiences show that the issue of deciding which binders perform well and which perform poorly is not easy. Certainly binder N2 is much more homogeneous than $\mathrm{N} 3$, yet it cracked while N3 survived the first winter. This was likely due to factors other than wax content and phase structure. Figure 3 shows that N2 ages at low temperatures by as much as $8.5^{\circ} \mathrm{C}$, and Figure 6 shows that this is likely due to a large asphaltene cluster size.

Binder AAE from the SHRP materials reference library is an oxidized Lloydminster and, similar to L5, shows no structure in the fluorescence and phase contrast microscope, yet it reversibly ages by a considerable amount. This shows that other factors not considered in this experimental study likely play an important role in the reversible aging process. It is possible that binders such as AAE and L5 produce coarser structures and perhaps wax crystals when cooled to low enough temperatures. It has been reported that air blowing increases the linear paraffin content. ${ }^{40}$ An alternate explanation could be that air blowing may lower the amount of mobile aliphatic carbons, ${ }^{41-43}$ causing an increased rate of reversible aging at low temperatures. Or, yet another explanation could be that the crystals were present but too small to be detected by the employed X-ray and optical techniques.

Binder E9 shows the most structure of all investigated materials and looks more like roofing asphalt, which typically has poor phase compatibility. It was offered to the Ministry of Transportation of Ontario (MTO) to address the early cracking concerns in the contracts that used $\mathrm{N} 1$ and $\mathrm{N} 2$ in a previous construction season. E9 grades under the AASHTO M320 criteria as a PG 52-40 but loses a significant $9{ }^{\circ} \mathrm{C}$ after 3 days of conditioning under LS-308. Further, this is one of the few binders investigated that continues to lose when stored for longer than 3 days, reaching the $-20^{\circ} \mathrm{C}$ mark after a month of storage at low temperatures. It is clear that a binder like this will seriously aggravate rather than mitigate transverse stress cracking in northern climates. The coarse phase structure as evident from both the fluorescence and phase contrast images shows that this material will also be likely to suffer from premature chemical aging due to volatilization and exudation (oil absorption by the aggregate). ${ }^{44}$

Experience from these studies has motivated the MTO to develop the extended BBR method, ${ }^{11}$ and it is hoped that in the near future the use of LS-308 in combination with the two newly developed fracture test methods, LS-298 ${ }^{13}$ and LS-299, ${ }^{12}$ will reduce the amount of premature and excessive cracking due to reversible aging processes and poor fracture resistance.

A final investigation involved a mass spectrometry analysis of saturates fractions from binders $\mathrm{T} 1$ and $\mathrm{T} 2$, which show very different reversible aging tendencies even though both are graded under Superpave as PG 64-34. The test section constructed with binder T1 is free of any damage after 3 years, while the section constructed with T2 was severely damaged,

(40) Gawel, I.; Czechowski, F. Petr. Sci. Technol. 1997, 15 (7\&8), 729742.

(41) Netzel, D. A.; Turner, T. F.; Forney, G. E.; Serres, M. Am. Chem. Soc. Div. Polym. Chem. Prepr. 1997, 38, 829.

(42) Netzel, D. A.; Michon, L. C.; Serres, M. L.; Wieseler, K. M. Proceedings of the 25th North American Thermal Analysis Society, McLean, VA, 1997; p 741

(43) Michon, L. C.; Netzel, D. A.; Turner, T. F.; Martin, D.; Planche, J.-P. Energy Fuels 1999, 13, 602-610.

(44) Van Gooswilligen, G.; De Bats, F. Th.; Harrison, T. Quality of Paving Grade Bitumen-A Practical Approach in Terms of Functional Tests. Proceedings of the Fourth Eurobitume Symposium, Madrid, Spain, October 1989; pp 290-297.

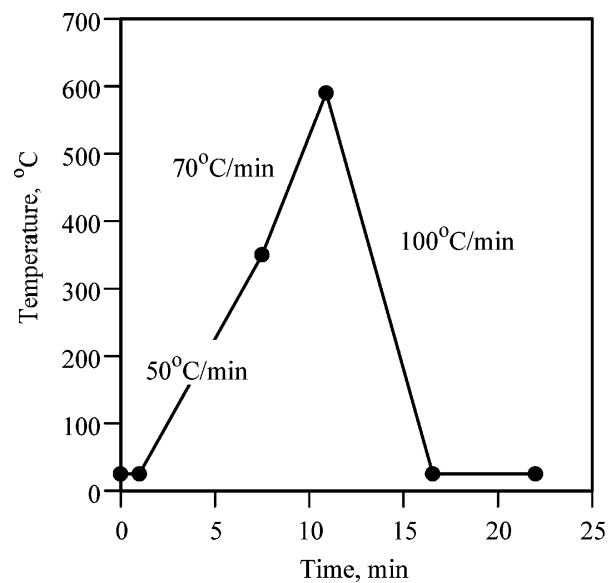

Figure 11. Temperature profile employed in mass spectrometry analysis of saturate fractions.
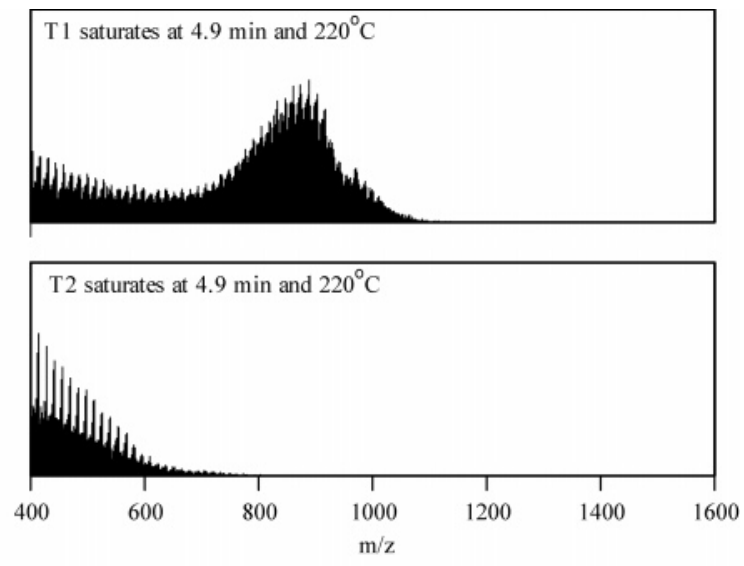

(a)

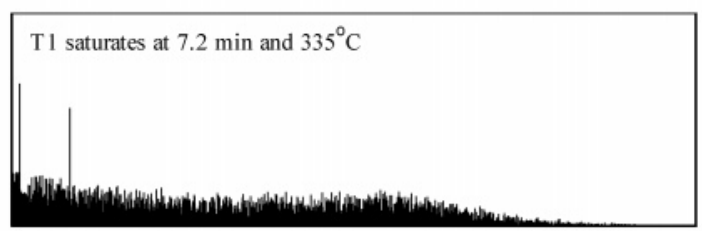

(b)

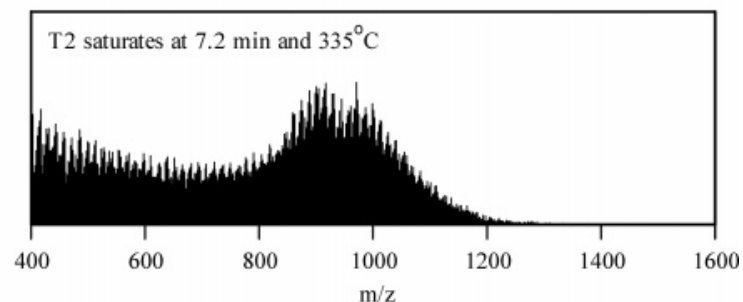

Figure 12. Mass spectrometry analysis data for saturate fractions from binders T1 and T2. (a) Volatile branched aliphatic components. (b) Nonvolatile linear aliphatic components.

with some $70 \mathrm{~m}$ of wheel-path cracks just 6 months after construction. Figure 3 shows that this divergence is likely due to the binders' respective reversible aging tendencies, with T2 losing $7.4{ }^{\circ} \mathrm{C}$ more than $\mathrm{T} 1$ after just 3 days of conditioning.

Asphaltenes and saturates were separated according to standard chromatographic techniques, and it was found that both binders had nearly equal asphaltene and saturates contents. However, the saturates fractions showed distinctly different appearances, with the material from $\mathrm{T} 1$ being a liquid at room temperature while the $\mathrm{T} 2$ fraction showed a semisolid appearance. Figure 11 shows the temperature profile employed in the mass spectrometry analysis, while Figure 12 shows the ion flux 
results for the two different fractions at two different times, 4.9 $\min \left(220^{\circ} \mathrm{C}\right)$ and $7.2 \mathrm{~min}\left(335^{\circ} \mathrm{C}\right)$. These data explain to a large extent the differences between the two materials. Saturates $\mathrm{T} 1$ contain more branched alkane structures (mobile aliphatics) and thus volatilize at lower temperatures, while saturates T2 contain more linear (crystallizable) alkanes and thus volatilize at higher temperatures. These results are in agreement with the microscope images as shown in Figure 9.

\section{Conclusions}

Reversible aging at low temperatures is a likely and serious cause of premature and excessive cracking at low temperatures. A $6{ }^{\circ} \mathrm{C}$ loss in low-temperature grade due to this process will reduce the confidence that a given road will not be exposed to damaging temperatures from the intended $98 \%$ to less than $50 \%$. $\mathrm{X}$-ray diffraction and mass spectra on whole and fractionated asphalt binders have shown that wax content is a major contributing factor to the reversible aging process. Large asphaltene clusters and small asphaltene sheet size are two other factors that contribute to the grade loss during conditioning at low temperatures. Coarse structures in fluorescence and phase contrast microscopy were found to aid in the explanation of reversible aging tendencies. It is unclear at present what other factors are of importance in the reversible aging process in selected oxidized binders with low detected wax content and asphaltene aggregation. A partial destruction of the mobile aliphatic fraction during the air-blowing process is one possible cause for the increased tendency of such binders to lose performance. Increased phase separation at lower temperatures would provide another equally reasonable explanation. However, further research is needed to provide conclusive evidence to support or refute such hypotheses.

\section{Further Work}

A successful round-robin test on the extended BBR protocol, with six industrial and government laboratories participating, has shown that the reproducibility is similar to the regular BBR method. It is now up to the user agencies to implement the developed test method in a way that is acceptable to all parties (users and producers). A 3-day cooling protocol in a purchase specification test method is obviously too long since it may put too much of a strain on the way in which asphalt binders are produced and sold. Hence, the test protocol could be used to allow certain asphalt cement suppliers to be put on a designated suppliers list. To get on the list, an asphalt supplier would have to meet the criteria associated with LS-308, as set by the user agency. Once a particular supplier is on the list, the user can then monitor periodically if the criteria are being met and take corrective action if necessary. In such a scenario, it is up to the supplier to make sure that the asphalt cement it sells is not high in wax and/or made with problematic upgrading technologies. The regular AASHTO M320 purchase specification can then remain largely in place. Such an approach would allow for substantial savings by excluding $10-20 \%$ of the worst performing asphalts (those that lose $7{ }^{\circ} \mathrm{C}$ and more after 3 days of conditioning).

Acknowledgment. The authors wish to thank the Highway Infrastructure Innovation Funding Program of the Ministry of Transportation of Ontario, Imperial Oil of Canada, the Innovations Deserving Exploratory Analysis (IDEA) program as administered through the National Cooperative Highway Research Program, and the Natural Sciences and Engineering Research Council of Canada for their financial support towards this research. Professor Paul Young of the Department of Biology at Queen's University and undergraduate student Irsan Kodrat of the Department of Chemistry helped with the collection of the microscope images. Michael Zhao and Patricia Yee helped with the collection of reversible aging data. Dr. Bernd Keller assisted with collection of the mass spectra. Their assistance is greatly appreciated.

EF060463B 